\title{
Salicornia Begolovi as Eco-Friendly Corrosion Inhibitor for Aluminum in Hydrochloric Acid Solution
}

\author{
A. S. Fouda ${ }^{1}$, S. M. Rashwan' ${ }^{2}$ A. E. Mohammed ${ }^{2}$ and A. M. Ibrahim² \\ ${ }^{1}$ Department of Chemistry, Faculty of Science, Mansoura University, \\ Mansoura-35516 and Department of Chemistry, Faculty of Science, Suez Canal \\ University,Ismailia-41522, Egypt
}

\begin{abstract}
THE INHIBITION effect of Salicornia Begolovi extract (SBE)as saving corrosion inhibitor foraluminum (Al) in1 $\mathrm{M} \mathrm{HCl}$ solution was studied using weight loss (WL), electrochemical impedance spectroscopy (EIS), electrochemical frequency modulation (EFM) and potentiodynamic polarization (PP) measurements.It was found that the Salicornia extract acts as a good inhibitor for aluminum corrosion in the acid solution. The inhibition efficiency (IE) increaseswithincreasing of both extract dose and temperature, indicating that this extract was adsorbed chemically on Al surface.PP studiesindicated that the extract acts as a mixed type inhibitor. EIS studies showed a reduction in the double layer capacitance and an increase in the charge transfer resistance. The adsorption of extract molecules was found to obey Temkinadsorption isotherm. The extract provides a good protection film to aluminumagainst corrosion in HClsolutions. Surface analysis was tested using scanning electron microscope (SEM). The results obtained from all investigated techniques are in good agreement.
\end{abstract}

Keywords : Acid inhibition, Aluminum, SBE, WL,EIS, EFM, SEM.

\section{Introduction}

Aluminum and its alloys represent an important category of materials due to their high technological value and wide range of industrial applications, especially in aerospace, automobile and household industries. Aluminum alloys enjoy a wide range of commercial usage due to their numerous desirable properties such as excellent mechanical properties, high strength, low density, lightweight, high thermal conductivity. However, they are reactive materials and are prone to corrosion [1]. Al-2Mg alloy is used for tank heating coils in crude-oil carriers. $\mathrm{HCl}$ is widely used in acid pickling, acid cleaning and oil well acidizing. Besides, acids increase rate of metal dissolution and are responsible for material failure indirectly. So,it is an importan to use corrosion inhibitors to decrease metal dissolution. The most important problem in this area of research is related to the protection of $\mathrm{Al}$ and its alloysagainst corrosion. One of the most important methods against the corrosion is to use inhibitors. The most role of inhibitor is to prevent the metal from the corrosive medium or to modify the electrode reactions that cause dissolution of the metal. Most of the efficient acid inhibitors are organic compounds that contain mainly nitrogen, sulphur or oxygen atoms in their structure [26]. The inhibition efficiency (IE)of organic compounds is strongly dependent on the structure and chemical properties of the layer formed on metals. Heterocyclic compounds are well known for their efficiencies as corrosion inhibitors and those containing nitrogen have been frequently referred to in the literature [7-9].Because of the broad spectrum of organic compounds available as corrosion inhibitors, there isincreasing concern about the toxicity of most corrosion inhibitors because they are toxic to living organism and may bepoison the earth [10]. These have promoted searches for green corrosion inhibitors. According to Eddy et al. [11], green corrosion inhibitors are biodegradable and do not contain heavy metals or other toxic compounds.

The use of photochemical as natural antimicrobial agents, commonly called 'biocides' is gaining popularity. The most essential of these bioactive constituents of plants are alkaloids, tannins, flavonoids and phenolic compounds. Many of the indigenous medicinal plants are used as spices and food. Phytoconstituents have found 
applications as naturally occurring antimicrobial agents in the field of preservation, pharmaceutics, phytopathology, etc. Increasing failure of chemotherapeutics and the resistance exhibited by pathogenic microbial infectious agents against antibiotics have led to the screening of medicinal plants for their potential antimicrobial activities. There are several reports regarding the antimicrobial activity of crude extracts prepared form plants. Some of the active principles of the bioactive compounds are preferred to for their therapeutic purposes either as a single entity or in combination, so as to inhibit the life processes of microbes. Of recent times, most of the industries are made by the use of natural materials for preservation [12].

The present research will discuss the Salicornia Begolovi extract (SBE) as a green corrosion inhibitor which as renewable source, friendly environmental acceptance, biodegradable, safer and cheaper than other green corrosion inhibitors for protecting $\mathrm{Al}$ in $1 \mathrm{M} \mathrm{HCl}$ medium.

\section{Experimental Methods}

\section{Materials and Solutions}

The working electrode for weight loss (WL) and electrochemical studies were prepared from Al specimens (99.98\%). The specimens were mechanically abraded with different grades of silicon carbide papers (320-2000)then washed with a double distilled water, and dried at room temperature. The aggressive solution used was prepared by dilution of analytical reagent grade $37 \% \mathrm{HCl}$ with double distilled water. The stock solution (1000 ppm) of SBE was used to prepare the desired doses by dilution with double distilled water. The concentration range of SBE used was 50-300 ppm.

\section{Preparation of plant extracts}

Fresh aerial parts of Salicornia Extractsample were crushed to make fine powder. The powdered materials $(250 \mathrm{~g})$ were soaked in $500 \mathrm{ml}$ of dichloromethane for 5 days and then subjected to repeated extraction with $5 \times 50 \mathrm{ml}$ until exhaustion of plant materials. The extracts obtained were then concentrated under reduced pressure using rotary evaporator at temperature below $50^{\circ} \mathrm{C}$. The dichloromethane evaporated to give solid extract which was cooled and stored at room temperature and ready for use as corrosion inhibitor.

\section{Weight loss (WL) technique}

The specimens dimension for the weight loss (WL) test were $2 \mathrm{~cm} \times 2 \mathrm{~cm} \times 2 \mathrm{~cm}$. Both sides of the specimens were exposed for WL test. After accurate weighing, the specimens were immersed in $250 \mathrm{ml}$ beaker, which contained $100 \mathrm{ml}$ of 1 $\mathrm{M}$ HClwith and without addition of different doses of SBE.All the aggressive acid solutions were open to air.Theinhibition efficiency for weight loss $\left(\% \mathrm{IE}_{\mathrm{wt}}\right)$ was evaluated after a preoptimized time interval of 3 hours using 50-300 ppm of the extract. After 3hours, the specimens were removed from the electrolyte, washed thoroughly with double distilled water, dried and weighed. The average weight loss of seven parallel aluminum sheets could be obtained. The inhibition efficiency $\left(\% \mathrm{IE}_{\mathrm{wt}}\right)$ and the degree of surface coverage, $\theta$ of SBE for the corrosion of $\mathrm{Al}$ were calculated as follows [13]:

$$
\% \mathrm{IE}_{w t}=\left[1-\frac{W}{w^{i}}\right] \times 100=\theta \times 100
$$

where $\mathrm{W}^{\circ}$ and $\mathrm{W}$ are the values of the average weight losses (mg) without and with addition of the extract, respectively.

\section{Electrochemical technique}

The electrochemicalexperiments were performed in a three-necked glass assembly containing $100 \mathrm{ml}$ of the electrolyte with different doses of extract (50-300 ppm). All electrochemical tests were carried out with Al sheet working electrode having an exposed area of $1 \mathrm{~cm}^{2}$. A conventional three-electrode cell consisting of $\mathrm{Al}$ as a working electrode, platinum foil as a counter electrode, and a saturated calomel electrode as a reference (SCE) electrode was used. All the measurements were done in solutions open to atmosphere under unstirred conditions. All potential values were reported versus SCE. Prior to each experiment, the electrode was abraded as before, washed with double distilledwater, and finally dried.Tafel polarization curves were obtained by changing the electrode potential automatically from $(-0.8$ to $1 \mathrm{~V}$ vs. SCE) at open circuit potential with sweep rate of $1 \mathrm{mVs}^{-1}$. For calculating the inhibition efficiency $\left(\% \mathrm{IE}_{\mathrm{p}}\right)$ and surface coverage $(\theta)$ the following formula was used:

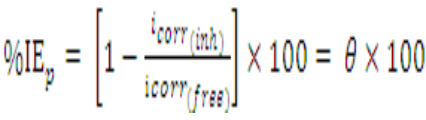


where $\mathrm{i}_{\text {corr(free) }}$ and $\mathrm{i}_{\text {corr(inh) }}$ are the corrosion current densities in the absence and presence of inhibitor, respectively.

Alternating current (AC) impedance measurements were acquired the frequency range of $2 \times 10^{4} \mathrm{~Hz}$ to $8 \times 10^{2} \mathrm{~Hz}$ at rest potential by applying $10 \mathrm{mV}$ sine-wave AC voltage. The experimental impedance was analyzed and interpreted based on the equivalent circuit. The charge transfer resistance $\left(\mathrm{R}_{\mathrm{ct}}\right)$ and the double layer capacitance $\left(\mathrm{C}_{\mathrm{dl}}\right)$ were determined from Nyquist plots. The inhibition efficiency $\left(\% \mathrm{IE}_{\mathrm{EIS}}\right)$ and the surface coverage $(\theta)$ were calculated from $\mathrm{R}_{\mathrm{ct}}$ values using the following formula:

$$
{ }_{61 E_{E S S}}=\left[1-\left(\frac{E_{*}^{*}}{E_{x}}\right)\right] \times 100=\theta \times 100
$$

where $\mathrm{R}_{\text {ct }}$ and $\mathrm{R}_{\mathrm{ct}}$ are the charge transfer resistance in the absence and presence of inhibitor, respectively.

Electrochemical frequency modulation, EFM, was carried out using two frequencies 2 and $5 \mathrm{~Hz}$. The base frequency was $0.1 \mathrm{~Hz}$, so the waveform repeats after $1 \mathrm{~s}$. The large peaks were used to calculate the corrosion current density $\left(\mathrm{i}_{\text {corr }}\right)$, the Tafel slopes $\left(\beta_{\mathrm{a}}\right.$ and $\left.\beta_{\mathrm{c}}\right)$ and the causality factors CF-2\&CF-3 [14].

Allelectrochemical tests were performed using Gamry Instrument (PCI4/750 Potentiostat/ Galvanostat/ZRA. This includes a Gamry framework system based on the ESA 400. Gamry applications include DC105 software for polarization, EIS300 software for EIS and EFM140 software for EFM measurements via computer for collecting data. Echem Analyst 6.03 software was used for plotting, graphing, and fitting data.To test the reliability and reproducibility of the measurements, triplicate experiments were conductedat the same conditions. For all tests, the electrode potential was allowed to stabilize $30 \mathrm{~min}$ before starting the measurements. All the experiments were conducted at $25^{\circ} \mathrm{C}$.

\section{Surface analysis}

For morphological study, surface features (2 $\mathrm{cm} \times 2 \mathrm{~cm} \times 2 \mathrm{~cm}$ ) of $\mathrm{Al}$ were examined before and after exposure to $1 \mathrm{M} \mathrm{HCl}$ solutions for one day with and without inhibitor. JEOL JSM-5500 scanning electron microscope was used for this investigation.

\section{Results and Discussion}

Potentiodynamic polarization technique

Potentiodynamic polarization(PP)curves recorded for $\mathrm{Al}$ in $1 \mathrm{M} \mathrm{HCl}$ solutions in the absence and presence of various doses of SBEat $25^{\circ} \mathrm{C}$ as shown in Fig. 1.The polarization curves remain almost the same in the absence of the extract, but in the presence of extract both anodic and cathodic branches shifted to the lower values of corrosion current densities compared to the blank solution. The electrochemical parameters derived from the polarization curves in Fig. 1 are given in Table 1.It is noted from this Table that $i_{\text {corr }}$ values decreases with the increase of the dose of extract, due to the increase in the blocked fraction of the Al surface by adsorption of extract components. The Tafel slopes of $\beta$ and $\beta$ at $25^{\circ} \mathrm{Cdo}$ not change remarkably upon addition of SBE, which indicates that both anodic and cathodic processes are controlled. A small shift in $\mathrm{E}_{\text {corr }}$ values towards positive direction was obtained in the presence of the extract indicating that the mixed nature of the extract. Generally, an inhibitor can be classified as cathodic or anodic type if the shift of corrosion potential in the presence of the inhibitor is more than $85 \mathrm{mV}$ with respect to that in the absence of the inhibitor $[15,16]$.In our test, the maximum shift is about $20-30 \mathrm{mV}$, which indicates that SBEcan be arranged as mixed-type inhibitor.

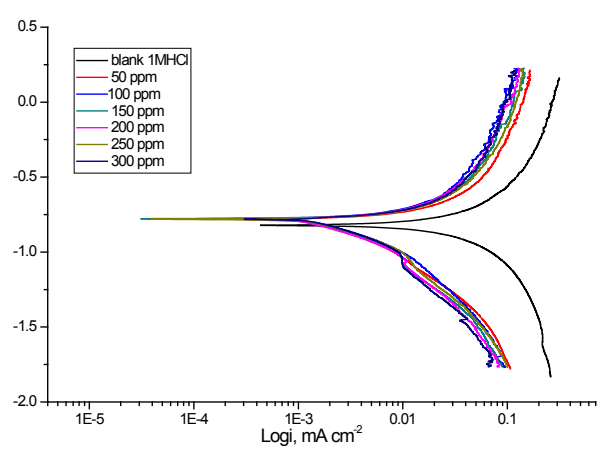

Fig.1. $\mathrm{PP}$ curves for the corrosion of $\mathrm{Al}$ in $1 \mathrm{M} \mathrm{HCl}$ solution without and with various doses of $\mathrm{SBE}$ at $25^{\circ} \mathrm{C}$.

Electrochemical impedance spectroscopy (EIS) technique

Nyquist plots for $\mathrm{Al}$ in $1 \mathrm{M} \mathrm{HCl}$ solution 
without and with various doses of SBE (50$300 \mathrm{ppm}$ ) are shown in Fig. 2. All Nyquist plots obtained were semicircle in nature, the diameter of the semicircles improved with improve in extract doses, and the shape remains constant through the test, indicating that the corrosion proceeds mainly under charge-transfer control and the presence of extract does not alter the mechanism of corrosion reaction.It is found that the obtained Nyquist plots are not perfect semicircle due to frequency dispersion and this behavior can be attributed to roughness and in- homogeneities of the electrode surface [17]. When there is nonideal frequency response, it is common practice to use distributed circuit elements in an equivalent circuit. The most widely employed is the constant phase element (CPE). In general a CPE is used in a model in place of a capacitor to compensate for in-homogeneity in the system [18]. The electrical equivalent circuit model shown in Fig. 3 was used to analyze the obtained impedance data. The model consists of the solution resistance $\left(\mathrm{R}_{\mathrm{s}}\right)$, the charge-transfer resistance of the interfacial corrosion reaction $\left(\mathrm{R}_{\mathrm{ct}}\right)$ and the constant phase angle element $(\mathrm{CPE})$. The value of frequency power (n) of CPE(-1 $\leq n \leq+1)$, can be assumed to correspond to capacitive behavior. However, excellent fit with this model was obtained with our experimental data. It was found that the diameters of the semicircle increases with increasing the dose of the investigated extract. This indicates that the polarization resistance of the oxide layer increases with increasing the dose of SBEand the depressed capacitive semicircle is often referred to the surface roughness and in-homogeneity, since this capacitive semicircle is correlated with dielectric properties and thickness of the barrier oxide film [19]. In addition, to the high frequency capacitive loop, the semi-circles rolled over and extended to the fourth quadrant, and a pseudo-inductive loop at low frequency end was observed, indicating that Faradic process is taking place on the free electrode sites. This inductive loop is generally attributed to the adsorption of species resulting from the $\mathrm{Al}$ dissolution and the adsorption of hydrogen [20]. The double layer capacitance $\left(\mathrm{C}_{\mathrm{d}}\right)$ for a circuit including a $\mathrm{CPE}$ was calculated from the following equation:

$$
\mathrm{C}_{\mathrm{dl}}=\mathrm{Y}_{\mathrm{o}}\left(\omega_{\mathrm{max}}\right)^{\mathrm{n}-}
$$

where $\omega_{\max }=2 \pi f_{\text {max }}, f_{\text {max }}$ is the frequency at which

TABLE 1. Electrochemical parameters calculated using PP technique for the corrosion of $\mathrm{Al}$ in $1 \mathrm{M}$ HClin the absence and presence of $\mathrm{SBE}$ at $25^{\circ} \mathrm{C}$.

\begin{tabular}{|c|c|c|c|c|c|c|c|}
\hline $\begin{array}{l}\text { [inh], } \\
\text { ppm }\end{array}$ & $\mathbf{m A}_{\text {corr }}$ & $\begin{array}{c}-E_{\text {corr' }} \\
m V \text { vs. SCE }\end{array}$ & $\underset{\text { mVdec }^{-1}}{\beta_{\mathrm{a}},}$ & $\underset{\text { mVdec }^{-1}}{\beta_{c},}$ & $\begin{array}{c}\text { C.R.X10-3 } \\
\text { mpy }\end{array}$ & $\boldsymbol{\theta}$ & $\%$ IE \\
\hline $1 \mathrm{M} \mathrm{HCl}$ & 48.3 & 821 & 240 & 390 & 207 & ----- & ---- \\
\hline 50 & 4.24 & 777 & 206 & 428 & 18.2 & 0.912 & 91.2 \\
\hline 100 & 3.1 & 780 & 138 & 486 & 13.2 & 0.935 & 93.5 \\
\hline 150 & 2.86 & 779 & 142 & 436 & 12.3 & 0.941 & 94.1 \\
\hline 200 & 2.72 & 779 & 150 & 407 & 11.6 & 0.944 & 94.4 \\
\hline 250 & 2.1 & 784 & 110 & 394 & 9.0 & 0.957 & 95.7 \\
\hline 300 & 1.77 & 775 & 120 & 394 & 7.6 & 0.964 & 96.4 \\
\hline
\end{tabular}

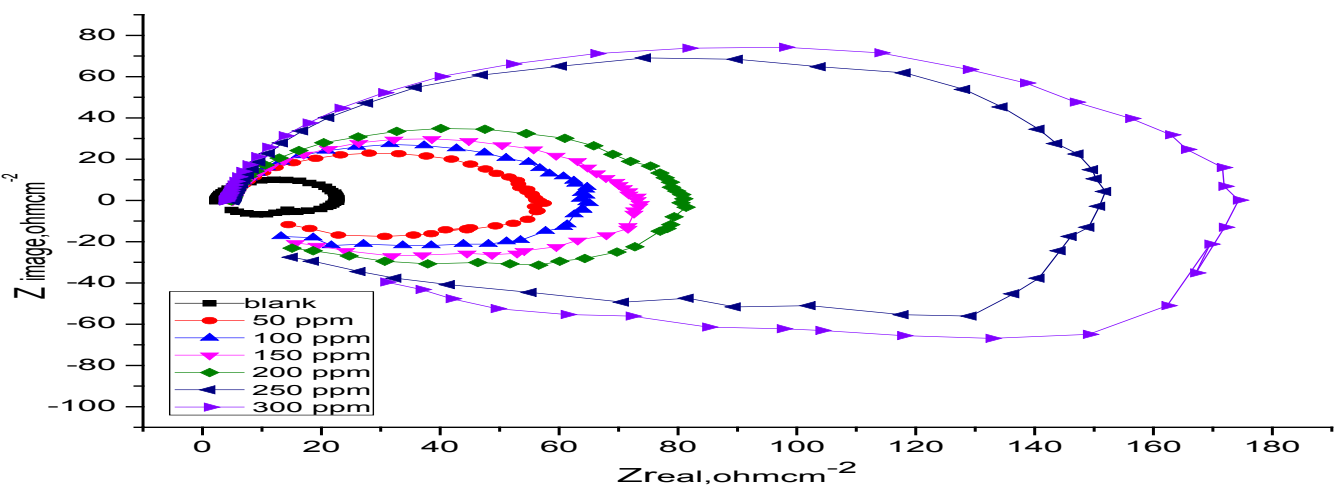

Fig. 2. Nyquist plots for $\mathrm{Al}$ in $1 \mathrm{M} \mathrm{HCl}$ solutions with and without various doses of $\mathrm{SBEat} 25^{\circ} \mathrm{C}$.

Egypt.J.Chem. 60 , No. 4 (2017) 


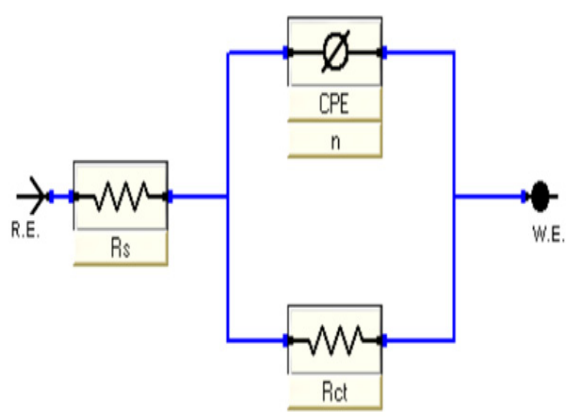

Fig. 3. Equivalent circuit used to model impedance data for Alin $1 \mathrm{M} \mathrm{HCl}$ solutions.

the imaginarycomponent of the impedance is maximaland $\mathrm{n}$ is the CPE exponent (phase shift).

The electrochemical parameters calculated from Nyquist plots using the equivalent circuit (Fig.3) are presented in Table 2.

Since the electrochemical theory assumed that $\left(1 / \mathrm{R}_{\mathrm{ct}}\right)$ is directly proportional to the capacity of double layer $\mathrm{C}_{\mathrm{dl}}$, the \% IE of the extract for Alin $1 \mathrm{M} \mathrm{HCl}$ solution was calculated from $\mathrm{R}_{\mathrm{ct}}$ values obtained from impedance data at different inhibitor doseby using equation (3).

From the impedance data given in Table 2, we can conclude that the value of $\mathrm{R}_{\mathrm{ct}}$ increases with the increase in the dose of the SBE and this indicates the formation of a protective film on the Al surface by the adsorption and an increase in the corrosion IE in acidic solution. While the value of $\mathrm{C}_{\mathrm{dl}}$ decreases with increasing the doses of the extract in comparison with that of blank solution (uninhibited), as a result from the replacement of water molecules by inhibitor molecules which lead to decrease in local dielectric constant and/or an increase in the thickness of the electric double layer formed on the metal surface [21].

Electrochemical frequency modulation (EFM) technique

EFM is a nondestructive corrosion measurement technique that can directly determine the corrosion current value without prior knowledge of Tafel slopes, and with only a small polarizing signal. These advantages of EFM technique make it an ideal candidate for online corrosion monitoring [22]. The great strength of the EFM is the causality factors which serve as an internal check on the validity of EFM measurement. The EFM intermodulation spectrums of $\mathrm{Al}$ in $1 \mathrm{M} \mathrm{HCl}$ solution containing (50-300ppm) of the SBEat $25^{\circ}$ Care shown in
Fig.4. The larger peaks were used to calculate the corrosion current density $\left(i_{\text {corr }}\right)$, the Tafel slopes $\left(\beta_{c}\right.$ and $\left.\beta_{\mathrm{a}}\right)$ and the causality factors $(\mathrm{CF}-2$ and $\mathrm{CF}-3)$ [23]. These electrochemical parameters are listed in Table 3 indicating that this extract inhibits the corrosion of Alin $1 \mathrm{M} \mathrm{HCl}$ through adsorption. The causality factors obtained under different experimental conditions are approximately equal to the theoretical values ( 2 and 3 ) indicating that the measured data are verified and of goodquality [24]. The IE $\mathrm{EFM}_{\mathrm{EF}}$ increases by increasing the studied extract doses and was calculated as follows:

$$
\text { WOE } E_{\text {ENM }}=\left(\frac{i_{\text {worr }} i_{\text {corr }}}{i_{\text {worr }}}\right) \times 100=\theta \times 100
$$

where $\mathrm{i}_{\text {corr }}^{\mathrm{o}}$ and $\mathrm{i}_{\text {corr }}$ are corrosion current densities in the non-existence and existence of SBE, respectively.

\section{Weightloss technique}

WL-time curves were carried out for Alin 1 $\mathrm{M} \mathrm{HCl}$ in the absence and presence of different doses of SBEat $25^{\circ} \mathrm{C}$ and are shown in Fig.5. The \%IE values calculated are listed in Table 4 . From thisTable, it is noted that the corrosionrate decreases and the \%IE increases as the dosesof $\mathrm{SBE}$ increases at $25^{\circ} \mathrm{C}$. The $\% \mathrm{IE}$ and surface coverage $(\theta)$ were calculated by equation (1). The observed inhibition action of the SBE could be attributed to the adsorption of its components on $\mathrm{Al}$ surface. The formed layer of the adsorbed molecules isolates the metal surface from the aggressive medium which limits the dissolution of Al by blocking of their corrosion sites and hence decreasing the corrosion rate, with increasing efficiency [25].

\section{Effect of temperature}

WL method was carried out at different temperatures $\left(25^{\circ} \mathrm{C}-45^{\circ} \mathrm{C}\right)$ in the presence of different doses of SBE. It has been found that the corrosion rate improves with improving in temperature for SBE (Table 5). The corrosion rate of Al in the absence of SBEincreased steeply from 25 to $45^{\circ} \mathrm{Cwhereas}$; in the presence of SBEthe corrosion rate decreased slowly. The rate of corrosion increases with increase in temperature (Table 5) and hence, increases in \% IE as shown in Fig. 6.

\section{Kinetic and thermodynamic study}

The corrosion parameter in the absence and presence of SBE in the temperature range $25-45^{\circ} \mathrm{C}$ has been summarized in Table 6. The Egypt.J.Chem. 60 , No. 4 (2017) 
TABLE 2. Electrochemical parametersobtained from EIS technique for the corrosion of Al $1 \mathrm{M} \mathrm{HCl}$ solutions with and without theexistence ofvarious does of $\mathrm{SBE}$ at $25^{\circ} \mathrm{C}$.

\begin{tabular}{|c|c|c|c|c|c|c|c|}
\hline $\begin{array}{l}\text { Conc, } \\
\text { ppm. }\end{array}$ & $\begin{array}{c}\mathbf{R}_{\mathrm{s}}, \\
\Omega \mathrm{cm}^{2}\end{array}$ & $\mathbf{n}$ & $\begin{array}{c}\mathbf{Y}^{0} \\
\mu \Omega^{-1} \mathbf{S c m}^{-2}\end{array}$ & $\begin{array}{c}\mathbf{R}_{\mathrm{ct}}, \\
\Omega \mathrm{cm}^{2}\end{array}$ & $\begin{array}{c}\mathrm{C}_{\mathrm{dl}}, \\
\mu \mathrm{F} \mathrm{\mathbf {cm } ^ { - 2 }}\end{array}$ & $\theta$ & $\%$ IE \\
\hline $1 \mathrm{M} \mathrm{HCl}$ & 2.4 & 0.872 & 32.0 & 11.8 & 7.9 & "----- & ----- \\
\hline 50 & 4.5 & 0.854 & 23.4 & 36.2 & 7.6 & 0.674 & 67.4 \\
\hline 100 & 4.4 & 1.03 & 5.0 & 36.5 & 6.7 & 0.677 & 67.7 \\
\hline 150 & 5.3 & 1.02 & 4.7 & 40.6 & 5.3 & 0.71 & 71.0 \\
\hline 200 & 5.2 & 1.0 & 4.3 & 43.1 & 4.4 & 0.727 & 72.7 \\
\hline 250 & 5.4 & 1.01 & 4.2 & 49.5 & 3.8 & 0.762 & 76.2 \\
\hline 300 & 3.9 & 1.0 & 2.8 & 77.1 & 3.0 & 0.847 & 84.7 \\
\hline
\end{tabular}

TABLE 3. Electrochemical kinetic parameters obtained by EFM technique for Alin1 M HClsolutions containing various doses of $\mathrm{SBE}$ at $25^{\circ} \mathrm{C}$.

\begin{tabular}{|c|c|c|c|c|c|c|c|c|}
\hline $\begin{array}{l}\text { [inh], } \\
\text { ppm }\end{array}$ & $\begin{array}{c}\mathbf{i}_{\text {corr }} \\
\mu \mathrm{A} \mathrm{cm}^{-2}\end{array}$ & $\begin{array}{c}\beta_{\mathrm{a}} \\
\mathrm{mV} \text { dec }^{-1}\end{array}$ & $\begin{array}{c}\beta_{\mathrm{c}} \\
\mathrm{mV} \text { dec }^{-1}\end{array}$ & $\begin{array}{c}\text { C.R.x10 } \\
\text { mpy }\end{array}$ & CF-2 & CF-3 & $\theta$ & $\%$ IE \\
\hline $1 \mathrm{MHCl}$ & 378 & 46 & 231 & 1.62 & 1.96 & 1.9 & ----- & ----- \\
\hline 50 & 294 & 39 & 143 & 1.26 & 1.8 & 1.7 & 0.223 & 22.3 \\
\hline 100 & 240 & 34 & 44 & 1.02 & 2.3 & 2.5 & 0.365 & 36.5 \\
\hline 150 & 192 & 29 & 58 & 0.825 & 2.3 & 2.1 & 0.50 & 50 \\
\hline 200 & 181 & 30 & 41 & 0.782 & 2.7 & 2.0 & 0.521 & 52.1 \\
\hline 250 & 169 & 29 & 48 & 0.726 & 2.2 & 2.1 & 0.553 & 55.3 \\
\hline 300 & 136 & 27 & 41 & 0.582 & 1.8 & 2.0 & 0.641 & 64.1 \\
\hline
\end{tabular}
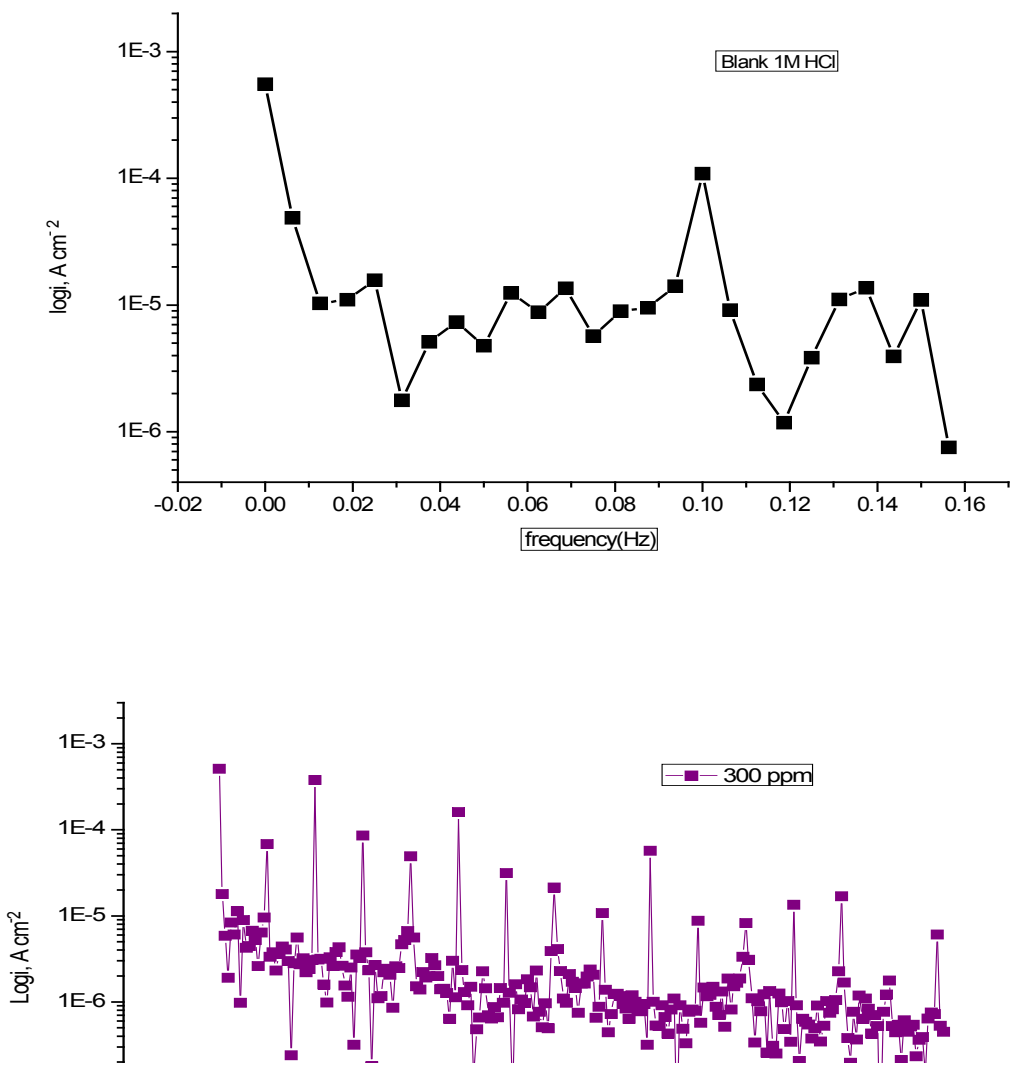

Fig. 4. Intermodulation spectrums for the corrosion of Alin $1 \mathrm{M}$ HClwithout and with various doses of SBEat $25^{\circ} \mathrm{C}$. 


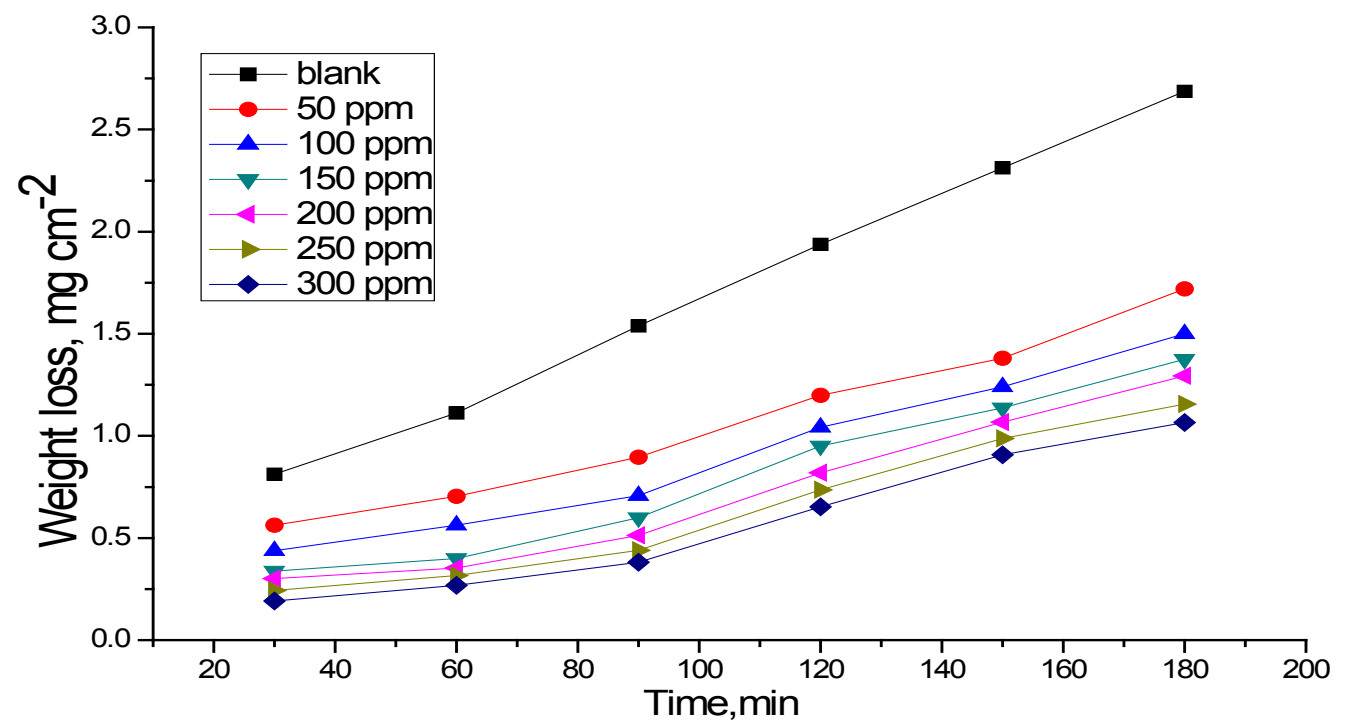

Fig. 5. WL-time curves for the corrosion of $\mathrm{Al}$ in $1 \mathrm{M} \mathrm{HCl}$ with and withoutexistence of different doses of SBE at $25^{\circ} \mathrm{C}$.

TABLE 4. WL measurements data forAlin $1 \mathrm{M}$ HCl solution with different doses of SBE after 120 minutes of immersion at $25^{\circ} \mathrm{C}$.

\begin{tabular}{|c|c|c|c|c|}
\hline $\begin{array}{l}\text { [Inh]. } \\
\text { ppm }\end{array}$ & $\begin{array}{c}\mathrm{WL}, \\
\mathrm{mg} \mathrm{cm}^{-2}\end{array}$ & $\begin{array}{c}\mathrm{k}_{\text {corr }} \times 10^{3} \\
\mathrm{mg} \mathrm{cm}^{-2} \mathrm{~min}^{-1}\end{array}$ & $\theta$ & $\% \mathrm{IE}$ \\
\hline $1 \mathrm{M} \mathrm{HCl}$ & 1.93 & 16.14 & ----- & ------- \\
\hline 50 & 1.11 & 9.26 & 0.426 & 42.6 \\
\hline 100 & 1.0 & 8.33 & 0.484 & 48.4 \\
\hline 150 & 0.951 & 7.92 & 0.509 & 50.9 \\
\hline 200 & 0.863 & 7.19 & 0.554 & 55.4 \\
\hline 250 & 0.813 & 6.77 & 0.581 & 58.1 \\
\hline 300 & 0.750 & 6.25 & 0.613 & 61.3 \\
\hline
\end{tabular}

apparent activation energy $\left(\mathrm{E}^{*}\right)$ for dissolution of Alin $1 \mathrm{M} \mathrm{HCl}$ was calculated from the slope of plots by using Arrhenius equation:

$\log k=\frac{-E_{a}^{*}}{2.303 R T}+\log A$

where $\mathrm{k}$ is rate of corrosion, $\mathrm{E}_{\mathrm{a}}^{*}$ is the apparent activation energy, $\mathrm{R}$ is the universal gas constant, $\mathrm{T}$ is absolute temperature and $\mathrm{A}$ is the Arrhenius pre-exponential factor.

By plotting $\log \mathrm{k}$ against $1 / \mathrm{T}$, the values of $\mathrm{E}^{*}$ a have been calculated $\left(\mathrm{E}^{*}=\right.$ slopex2.303 x R) in Fig.
7. $E^{*}$ valuesincrease in the presence of SBEfor Alin $1 \mathrm{M} \mathrm{HCl}$ (Table 6). The decrease in $\mathrm{E}^{*}{ }_{\mathrm{a}}$ with increase inhibitor dose of extract is typical of chemisorptiondue to the chemical bonds were strengthen byincreasing temperatureof energy barrier on the $\mathrm{Al}$ surface and its thickness increases by increasing the doses. This indicative to the physical adsorption of extract molecules on the Al surface as reported before [26]. The values of change of entropy $\left(\Delta \mathrm{S}^{*}\right)$ and change of enthalpy $\left(\Delta \mathrm{H}^{*}\right)$ can be calculated by using the formula: 


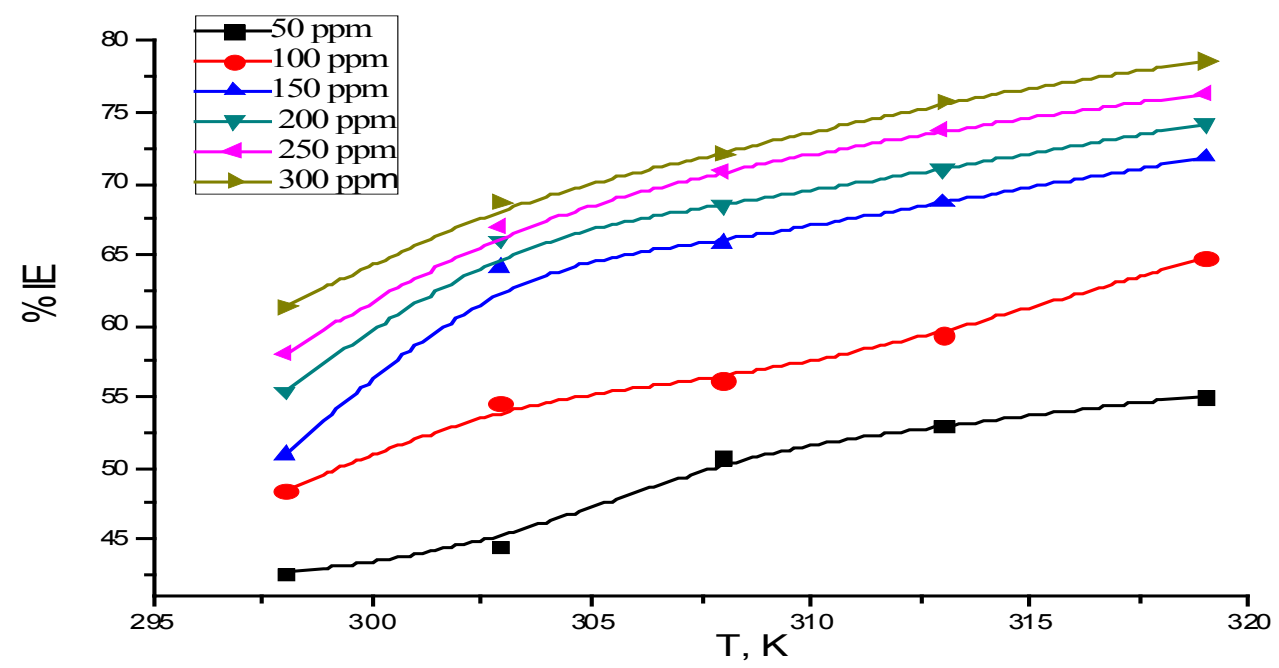

Fig. 6. Effect of temperature on \%IE using various doses of SBE on $\mathrm{Al}$ surface in $1 \mathrm{M} \mathrm{HCl}$ at different temperatures.

TABLE 5. Data of WL measurementsfor Alin $1 \mathrm{M} \mathrm{HCl}$ solution with different doses of SBE after $120 \mathrm{~min}$ of immersion at $30-45^{\circ} \mathrm{C}$.

\begin{tabular}{|c|c|c|c|c|c|}
\hline$\%$ IE & $\theta$ & $\begin{array}{c}\mathbf{k}_{\text {corr }} \mathbf{x} 10^{3} \\
\mathrm{mg} \mathrm{cm}^{-2} \mathbf{m i n}^{-1}\end{array}$ & $\begin{array}{c}\text { WL, } \\
\mathbf{m g ~ c m}^{-2}\end{array}$ & $\begin{array}{l}{[\mathrm{Inh}] .} \\
\text { ppm }\end{array}$ & $\begin{array}{l}\text { Temp., } \\
\text { K }\end{array}$ \\
\hline ------- & ----- & 33.03 & 3.96 & Blank & \multirow{8}{*}{303} \\
\hline 43.2 & 0.432 & 18.96 & 2.27 & 50 & \\
\hline 55.5 & 0.555 & 14.58 & 1.75 & 100 & \\
\hline 64.4 & 0.644 & 11.77 & 1.41 & 150 & \\
\hline 65.3 & 0.653 & 11.45 & 1.37 & 200 & \\
\hline 67.8 & 0.678 & 10.61 & 1.27 & 250 & \\
\hline 68.4 & 0.684 & 10.02 & 2.16 & 300 & \\
\hline ------- & -------- & 64.86 & 7.78 & Blank & \\
\hline 51.9 & 0.519 & 31.11 & 3.73 & 50 & \multirow{7}{*}{308} \\
\hline 55.8 & 0.558 & 27.34 & 3.28 & 100 & \\
\hline 65.3 & 0.653 & 21.83 & 2.62 & 150 & \\
\hline 68.5 & 0.685 & 20.41 & 2.45 & 200 & \\
\hline 70.9 & 0.709 & 18.83 & 2.26 & 250 & \\
\hline 72.1 & 0.721 & 13.85 & 4.62 & 300 & \\
\hline ------ & -------- & 159.22 & 19.11 & Blank & \\
\hline 52.2 & 0.522 & 75.92 & 9.11 & 50 & \multirow{6}{*}{313} \\
\hline 59.4 & 0.594 & 64.56 & 7.74 & 100 & \\
\hline 68.7 & 0.6389 & 49.82 & 5.98 & 150 & \\
\hline 71 & 0.710 & 46.16 & 5.54 & 200 & \\
\hline 73.8 & 0.738 & 41.71 & 5.00 & 250 & \\
\hline 75.78 & 0.7578 & 38.42 & 4.62 & 300 & \\
\hline ----- & ----- & 218.70 & 26.25 & Blank & \multirow{7}{*}{318} \\
\hline 54.7 & 0.547 & 99.23 & 11.90 & 50 & \\
\hline 61.9 & 0.619 & 83.68 & 10.06 & 100 & \\
\hline 71.8 & 0.71 .8 & 61.75 & 7.41 & 150 & \\
\hline 74.2 & 0.742 & 56.49 & 6.77 & 200 & \\
\hline 76.3 & 0.763 & 52.11 & 6.25 & 250 & \\
\hline 78.6 & 0.786 & 46.86 & 5.62 & 300 & \\
\hline
\end{tabular}

Egypt.J.Chem. 60 , No. 4 (2017) 


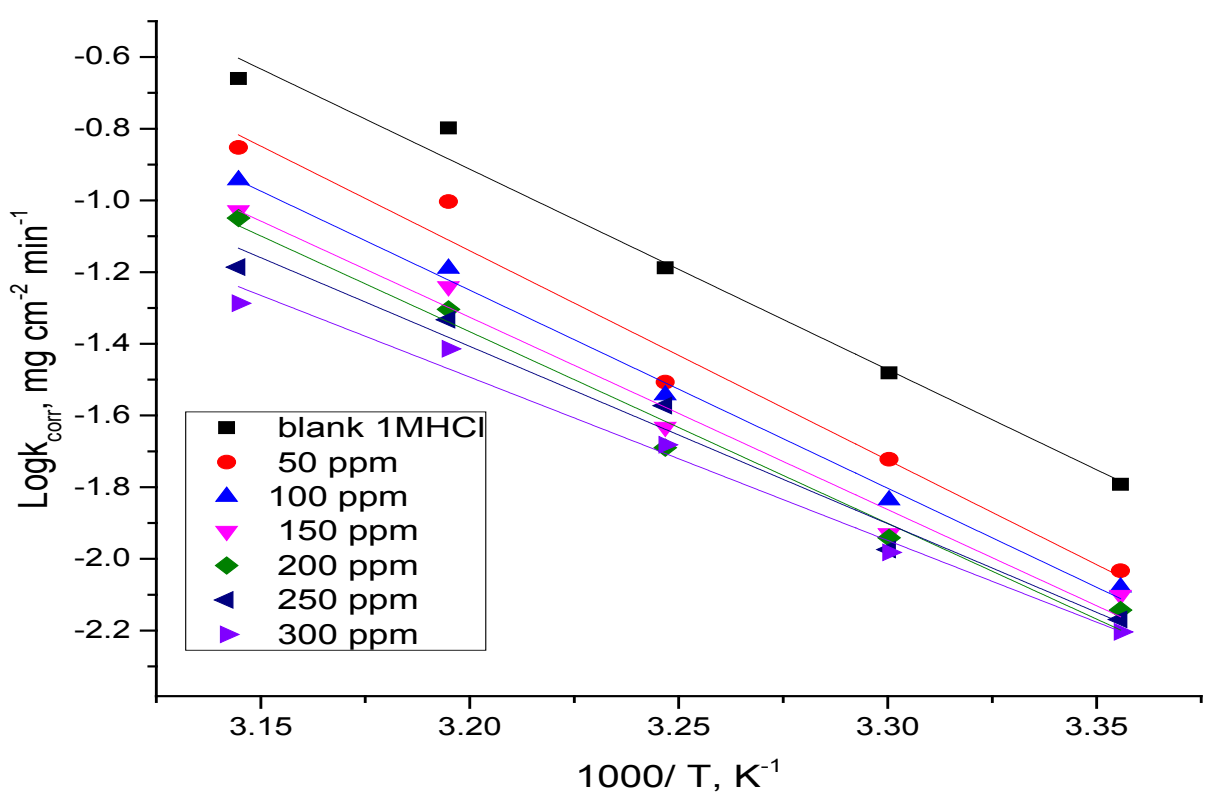

Fig. 7. Arrhenius plot (logk vs.1/T)for Alin $1 \mathrm{M}$ HClwith and without presence of various concentrations ofSBE

$$
k=\left(\frac{R T}{N h}\right) \exp \left(\frac{\Delta S^{*}}{R}\right) \exp \left(\frac{\Delta H^{*}}{R T}\right)
$$

where h is Planck's constant, $\mathrm{N}$ is Avogadro number.

A plot of $\log (\mathrm{k} / \mathrm{T})$ vs. 1/T (Fig. 8) should give a straight line, with a slope of $\left(\Delta \mathrm{H}^{*} / 2.303 \mathrm{R}\right)$ and an intercept of $\left[\log (\mathrm{R} / \mathrm{Nh})+\Delta \mathrm{S}^{*} / 2.303 \mathrm{R}\right]$, from which the values of $\Delta \mathrm{S}^{*}$ and $\Delta \mathrm{H}^{*}$ can be calculated (Table 6). The positive signs of the enthalpies $\left(\Delta \mathrm{H}^{*}\right)$ reflect the endothermic nature of the $\mathrm{Al}$ dissolution process. decreasing inthe values of $\Delta \mathrm{S}^{*}$ for the extractimply that activated complex in the rate-determining step represents thedissociationrather than association step, indicating that anincrease in disorder takes place on going from reactants to the activated complex [27]. The positive sign of $\Delta H^{*}$ revealed the endothermic nature of the corrosion process.
Generally, an endothermic process indicates chemisorption. various concentrations of SBE.

\section{Adsorption isotherms}

The adsorption isotherms were conducted to have more insight into the mechanism of corrosion inhibition. Because the IE of metals is usually due to either the adsorption of the inhibitor molecules on the metal surface or the formation of a film of insoluble metal complexes [28].To obtain the adsorption isotherms, the degree of surface coverage obtained from WL method was determined as a function of dose extract. The values of $\theta$ were then plotted to fit the most suitable model of adsorption [29].To determine the adsorption mode, Temkin adsorption isothermas shown in Fig. 9 was found to be the best, which give a straight line graph for the plot of $\theta$ versus concentration $\log \mathrm{C}[30]$. An adsorption isotherm gives the relation between the coverage of an interface with the adsorbed species and the dose of the species in solution. Interpretation of the performance of the adsorbent type of

TABLE 6. Activation parameters for dissolution of Alin the absence and presence of different doses of SBE in $1 \mathrm{M} \mathrm{HCl}$

\begin{tabular}{|lccc|}
\hline $\begin{array}{l}\text { [inh], } \\
\mathbf{p p m}\end{array}$ & $\begin{array}{c}-\mathbf{E}_{\mathbf{a}}^{*}, \\
\mathbf{k J} \mathbf{~ m o l}^{-\mathbf{1}}\end{array}$ & $\begin{array}{c}\Delta \mathbf{H}^{*}, \\
\mathbf{k J ~} \mathbf{~ m o l}^{-\mathbf{1}}\end{array}$ & $\begin{array}{c}\Delta \mathbf{S}^{*}, \\
\mathbf{J ~ m o l}^{-\mathbf{1}} \mathbf{K}^{-\mathbf{1}}\end{array}$ \\
\hline $1 \mathrm{M} \mathrm{HCl}$ & 107 & 105 & 74 \\
50 & 111 & 110 & 83 \\
100 & 105 & 104 & 62 \\
150 & 102 & 100 & 51 \\
200 & 102 & 98 & 48 \\
250 & 94 & 92 & 22 \\
300 & 87 & 86 & 2 \\
\hline
\end{tabular}


inhibitor can be enhanced by fitting the data in one of known adsorption isotherm which is represented in Fig. 9. Temkin adsorption isotherm [31] fits well the experimental data.

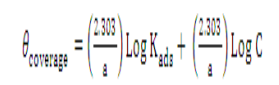

where $\mathrm{K}_{\mathrm{ads}}$ is the adsorption equilibrium constant and " $a$ " (heterogeneous factor of metal surface) is a molecular interaction parameter depending upon molecular interactions.

A plot of $\theta$ versus $\log$ Cshould give straight lines with slope equals (2.303/a) and the intercept is $(2.303 / \mathrm{a}) \log \mathrm{K}$ ads. The experimental data give good curves fitting for the applied adsorption isotherm as the correlation coefficients $\left(\mathrm{R}^{2}\right)$ close to unit. The values obtained of " $\mathrm{a}$ " , $\mathrm{K}_{\mathrm{ads}}$ and $\Delta \mathrm{G}^{\circ}$ ads are given in Table $7 . \mathrm{K}_{\text {ads }}$ can be calculated from the intercept of fitting formula in Fig 9. The relationship of $\mathrm{K}_{\text {ads }}$ and standard free energy $\left(\Delta \mathrm{G}_{\text {ads }}^{\circ}\right)$ can be expressed by Eq. 10 .

$$
\vec{J}_{\mathrm{ads}}^{\circ}=-R T \ln \left(55.5 K_{\mathrm{ads}}\right)
$$

where 55.5 is the molar concentration of water in $\mathrm{M}^{-1}$.

The negative value of $\Delta \mathrm{G}^{\circ}{ }_{\text {ads }}$ indicatesspontaneous adsorption of the extract molecules on Al surface. Hence, the values of $\Delta \mathrm{G}^{\circ}{ }_{\text {ads }}$ calculatedwere $\left(36.1-45.4 \mathrm{~kJ} \mathrm{~mol}^{-1}\right)$ (Table 7) again supporting the earlier proposed mixed (physisorption and chemisorption) mechanism. $\Delta \mathrm{G}^{\circ}{ }_{\text {ads }}$ value up to $\left(-20 \mathrm{~kJ} \mathrm{~mol}^{-1}\right)$ is consistent with physical adsorption mechanism while that more negative than $\left(-40 \mathrm{kJmol}^{-1}\right)$ defines chemical adsorption mechanism [32]. $\mathrm{K}_{\text {ads }}$ values decrease with rise in temperature (Table 7). $\mathrm{K}_{\text {ads }}$ values are indicative of the strength between adsorbate and adsorbent [33], their values increase with rise in temperature. This also support the chemical mechanism, the heterogeneous factor of metal surface $(a>0)$ positive value show that there is a molecular interaction between the layer of inhibitor and the surface of Al.Also an endothermic adsorption process $\left(\Delta \mathrm{H}^{\circ}{ }_{\text {ads }}>0\right)$ may involve chemisorption. For physisorption adsorption $\Delta \mathrm{H}^{\mathrm{o}}{ }_{\text {ads }}=41.86 \mathrm{~kJ} \mathrm{~mol}^{-1}$ but for chemisorption adsorption $\Delta \mathrm{H}^{\mathrm{o}}{ }_{\text {ads }}=100 \mathrm{~kJ} \mathrm{~mol}^{-1}$ [34].Plot of $\left(\Delta \mathrm{G}^{\mathrm{o}}{ }_{\mathrm{ads}}\right)$ versus Tas shown in Fig.10 according to the thermodynamic basic equation:

$$
\Delta G_{\mathrm{ads}}^{\circ}=\Delta H_{\mathrm{ads}}^{\circ}-T \Delta S_{\mathrm{ads}}^{\circ}
$$

In our results the calculated value of $\Delta \mathrm{H}_{\text {ads }}^{\mathrm{o}}=93.5 \mathrm{~kJ} \mathrm{~mol}^{-1}$ which indicates that the adsorption of the extract on Al surface is a chemisorption process. Large negative value $\Delta \mathrm{S}^{\circ}{ }_{\mathrm{ads}}=-436 \mathrm{~J} \mathrm{~mol}^{-1} \mathrm{~K}^{-1}$ indicates that decreasing in disorder of corrosion process on $\mathrm{Al}$ surface in $1 \mathrm{M}$ $\mathrm{HCl}$ using SBE as corrosion inhibitor (Table 7).

\section{Scanning Electron Microscopy (SEM) technique}

Figure 11a shows SEMmicrographs of the polished Alsample. Figure $11 \mathrm{~b}$ shows the SEM micrographs of $\mathrm{Al}$ when exposed to $1 \mathrm{M} \mathrm{HCl}$ solution at room temperature in the absence of extract. This figure shows that, the Al surface appears to be very rough in the absence of extract. This is due to formation of uniform flake-type corrosion products on Al surface. No corrosion and other separate phases are visible in the micrographs. Fig. $11 \mathrm{c}$ shows the micrographs of the metal surface when exposed to the acid medium in the presence of 300 ppm of the extract, at the same magnification. In this micrograph the $\mathrm{Al}$ surface was found to be covered with smooth protective film of compounds uniformly spread over the surface as previously reported [35]. The protective film is formed due to the adsorption of the extract molecules on $\mathrm{Al}$ surface.

\section{Mechanism of corrosion inhibition}

Adsorption of SBEwhich contains fatty acid and hydrocarbon can be explained on the basis that adsorption of the extract was mainly via hetero atoms present in different constituents of extract in addition to the availability of $\pi$ - electrons in the aromatic system [36]. The phytoconstituents of SBEinclude fatty acid and hydrocarbons such as Tannins, Flavonoids, Saponins, Cardiac glycosides, Steroids, Phlobatannins and Terpenoids, etc. The above phytochemical constituents present in SBE having many active centers at hetero atoms which are regarded as centers of adsorption. Where the results of temperatures study have shown that mechanical adsorption takes place through the chemicaladsorption. It was found that Al surface in acid media has a positive chargewhich have vacant d- orbital [37] which leads to coordination bond of the negatively charge species. In aqueous acidic solutions,main constituents of SBE exists as neutral molecules or as protonated molecules (cations). So in view of the above the adsorption mechanism may occur as follows: First $\mathrm{Cl}^{-}$anions adsorb chemically on positively charged Al surface, resulting that the $\mathrm{Al}$ surface became negatively charged. The protonated extract molecules then get adsorbed on the negatively charged Al surface. 


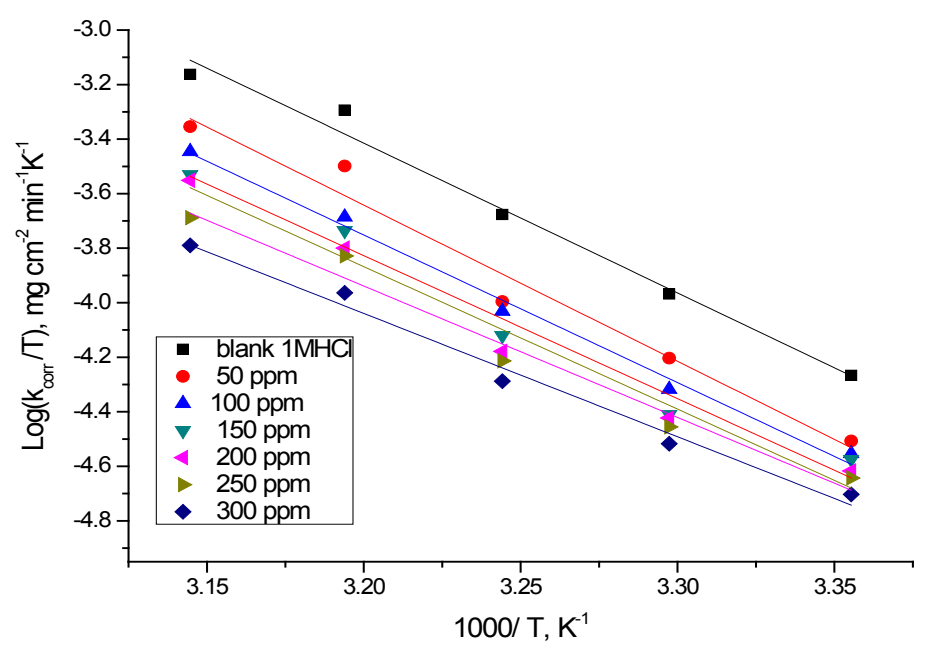

Fig. 8. Transition-state $(\log \mathrm{k} / \mathrm{T}$ vs. $1 / \mathrm{T})$ curves for Alin $1 \mathrm{M}$ HClwith and without presence of various concentrations of SBE.

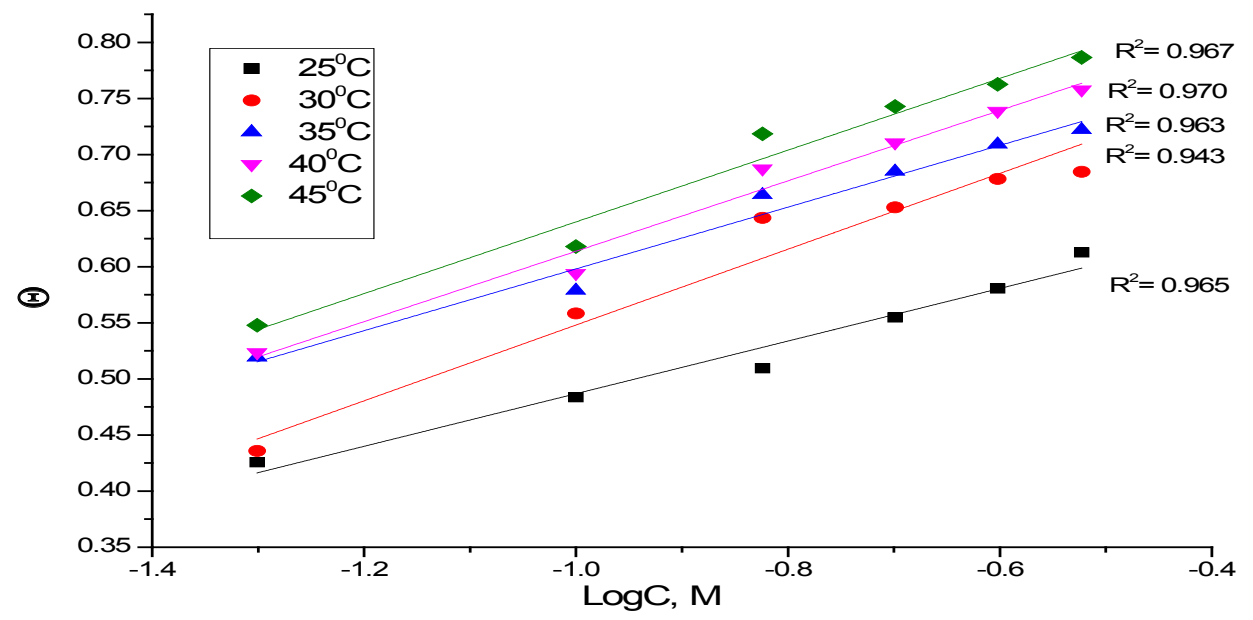

Fig. 9. Temkin adsorption plots for Alin $1 \mathrm{M} \mathrm{HCl}$ containing various doses of $\mathrm{SBE}$ at $25^{\circ} \mathrm{C}$

TABLE 7. Thermodynamic parameters for the adsorption of SBEon Alsurface in $1 \mathrm{M}$ HClat various temperatures.

\begin{tabular}{|lccccc|}
\hline $\begin{array}{l}\text { Temperature, } \\
\mathrm{K}\end{array}$ & $\mathrm{a}$ & $\begin{array}{c}\mathrm{Log} \mathrm{K} \text { ads } \\
\mathrm{M}^{-1}\end{array}$ & $\begin{array}{c}-\Delta \mathrm{G}_{\text {ads }}^{\mathrm{o}} \\
\mathrm{kJ} \mathrm{mol}^{-1}\end{array}$ & $\begin{array}{c}\Delta \mathrm{H}_{\text {ads }}^{\mathrm{o}} \\
\mathrm{kJ} \mathrm{mol}^{-1}\end{array}$ & $\begin{array}{c}-\Delta \mathrm{S}^{\mathrm{o}} \\
\mathrm{J} \mathrm{mols}^{-1} \mathrm{~K}^{-1}\end{array}$ \\
\hline 298 & 9.8 & 4.571 & 36.1 & & \\
303 & 8.7 & 5.007 & 39.2 & & 436 \\
308 & 8.3 & 5.119 & 40.5 & 93.5 & \\
313 & 8.1 & 5.279 & 42.4 & & \\
318 & 8.1 & 5.711 & 45.4 & & \\
\hline
\end{tabular}




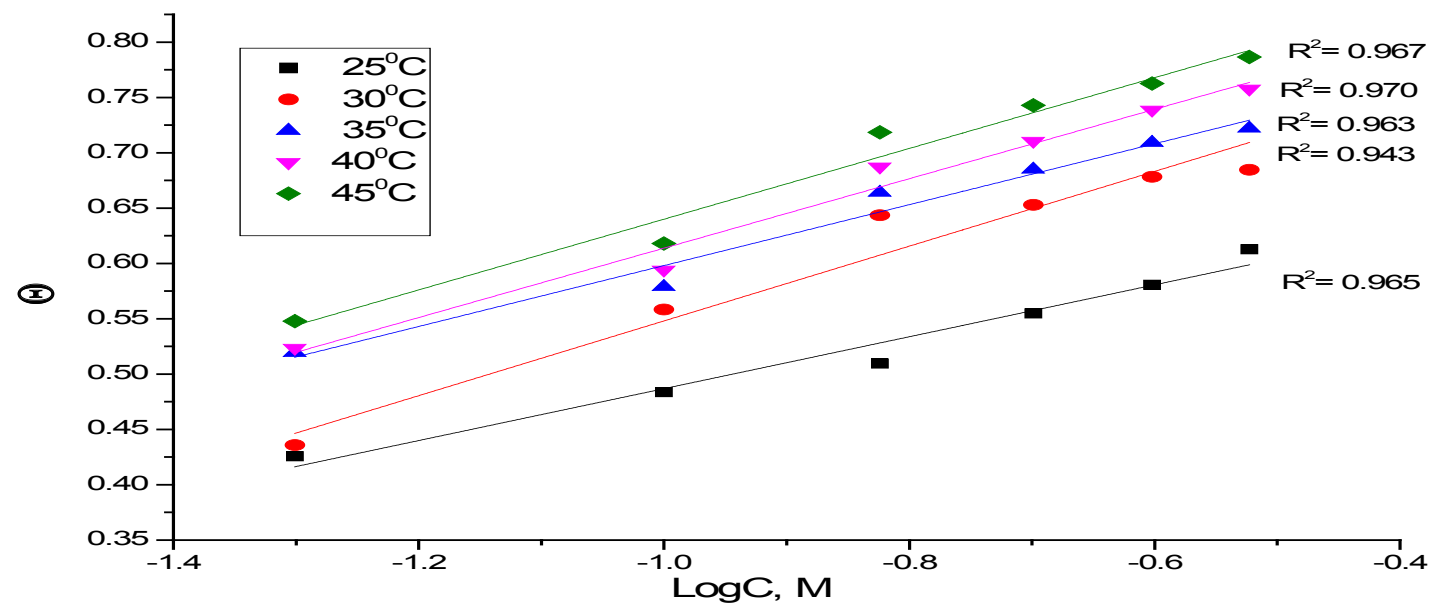

Fig. 9. Temkin adsorption plots for Alin $1 \mathrm{M} \mathrm{HCl}$ containing various doses of $\mathrm{SBE}$ at $25^{\circ} \mathrm{C}$

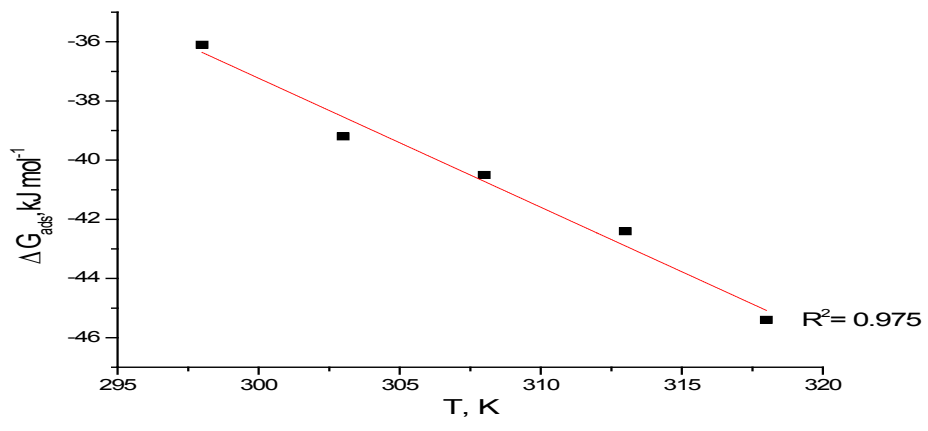

Fig.10. Variation of $\Delta \mathrm{G}^{\mathrm{o}}$ ads versus $\mathrm{T}$ for the adsorption of SBE on $\mathrm{Al}$ surface in $1 \mathrm{M} \mathrm{HCl}$ at different temperatures

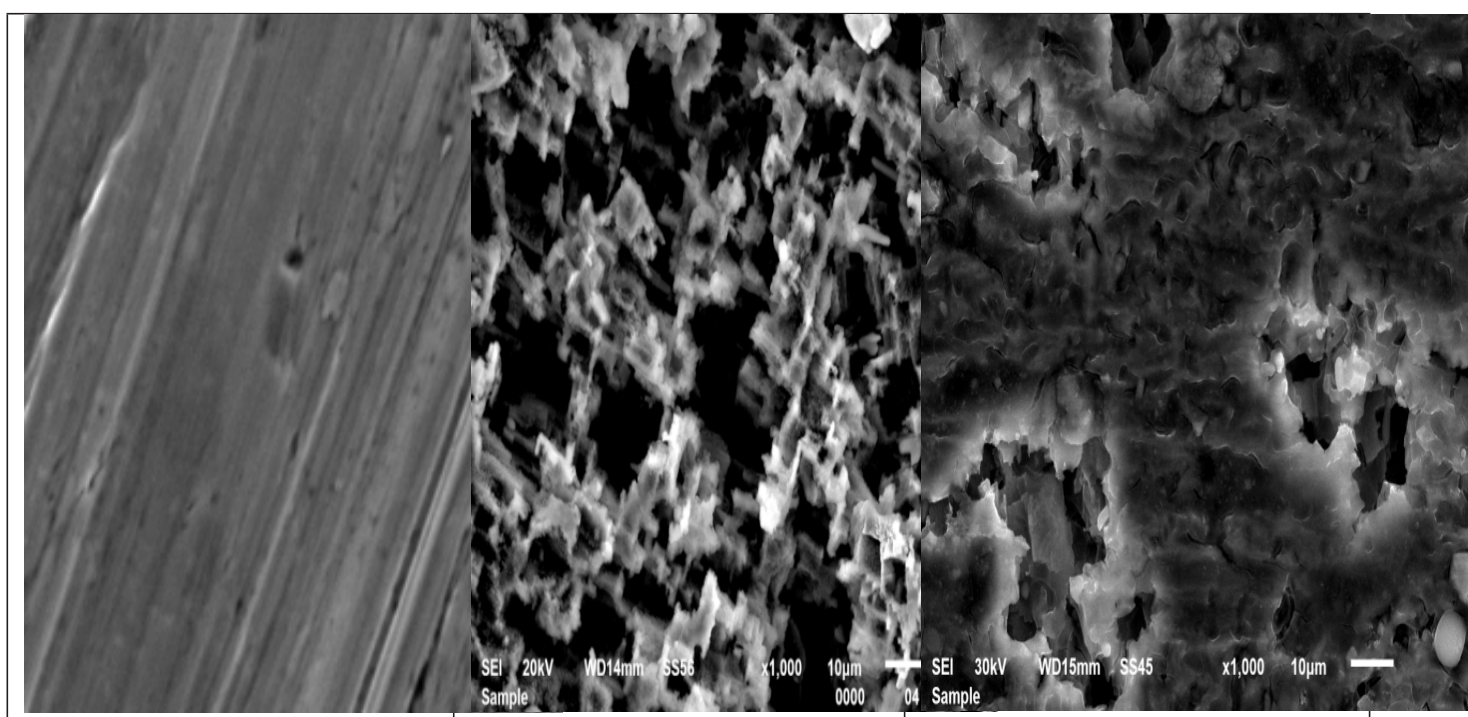

(a)

(b)

(C)

Fig. 11. SEM micrographs of Alsurface (a) before immersion in $1 \mathrm{M} \mathrm{HCl}$, (b) after $24 \mathrm{hr}$ immersion in 1 M HCland (c) after $24 \mathrm{hr}$ immersion in $1 \mathrm{MHCl}+300 \mathrm{ppm}$ of SBEat $25^{\circ} \mathrm{C}$.

Egypt.J.Chem. 60 , No. 4 (2017) 


\section{Conclusions}

The results obtained from all methods showed that the inhibiting action increases with increasesthe SBE doses and with the increasing the solution temperature (chemical adsorption). Increasing the dose of the SBE, decreasingthe double layer capacitances and increasing the charge transfer resistance.The adsorption of plant extract molecules on the Al surface follows Temkin adsorption isotherm.Tafel polarization results indicate that, this extract component act as mixed-type inhibitor. The inhibition efficiencies determined by WL, PP, EFM and EIS techniques are in reasonably good agreement.SEM micrographs indicate that this extract is adsorbed on $\mathrm{Al}$ surface forming a protective film.

\section{References}

1. Mountarlier, V., Gigandet, M.P., Normand, B., and Pagetti, J., EIS characterization of anodic films formed on 2024 aluminum alloyin sulphuric acid containing molybdate or permanganate species. Corros.Sci., 47, 937 (2005).

2. Fox PG and Bradley PA, 1,2,4-triazole as a corrosion inhibitor for copper, Corros. Sci., 20, 643 (1990).

3. El Sayed, A., Phenothiazine as inhibitor of the corrosion of cadmium in acidic solutions, J. Appl. Electrochem., 27,193 (1992).

4. Schmitt, G.,Application of Inhibitors for Acid Media: Report prepared for the European Federation of Corrosion Working Party on Inhibitors, Br. Corros. J.,19,165 (1984).

5. Sykes, M., Silver Jubilee reviews 25 years of progress in electrochemical methods, Br. Corros. J. 25, 175 (1990).

6. Chatterjee, P., Banerjee, MK. and Mukherjee, P.,Synergistic inhibition of inorganic anions with pyridine-derivatives for steel in hydrochloric-acid, Ind. J. Technol.,29, 191 (1991).

7. Osman, M.M., Khamis, E. andMichael A.,Corrosioninhibition of steel by triazolidines in saline water.,Corros. Prev. Control, 41, 60 (1994).

8. Bilgic, S. andCaliskanN., An investigation of some schiff bases as corrosion inhibitors for austenite chromium nickel steel in $\mathrm{H}_{2} \mathrm{SO}_{4}$., Appl. Electrochem. 31, 79 (2001).

9. Quraishi, MA.andSardar, R., Dithiazolidines -A new class of heterocyclicinhibitors for prevention of mild steel corrosion in hydrochloric acid solution. Corros. Sci., 58, 103 (2002).

10. Okon Eddy N. , I. Ita B., N. Dodo S. and D.
Paul E., Inhibitive and adsorption properties of ethanol extract of Hibiscus sabdariffa calyx for the corrosion of mild steel in $0.1 \mathrm{M} \mathrm{HCl} ., 5,43$ (2012)

11. Eddy, N.O., Ibok, U.J. and Ebenso, E.E. J., Adsorption, synergistic inhibitive effect and quantum chemical studies of ampicillin(AMP) and halides for the corrosion ofmild steelin $\mathrm{H}_{2} \mathrm{SO}_{4}$.,Appl.Electrochem., 40, 445 (2010).

12. Santhanakrishnan, D., shankarb, Sripriya N. and Chandrasekaran, B., studies on the phytochemistry, spectroscopic characterization and antibacterial efficacy of salicorniabrachiata, Int $\mathrm{J}$ Pharm Pharmsci, 6, 430 (2014).

13. Mccafferty, E., Lewis Acid/Lewis Base effects in corrosion and polymer adhesion at Al surfaces, $J$. Electrochem. Soc., 150, 342 (2003).

14. El-Dahan, H.A., Soror T.Y. and El-Sherif R.M., Studies on the inhibition of aluminum dissolution by hexamine-halide blends, Mater.Chem.Phys., 89, 268 (2005).

15. Tao, Z., Zhang, S., Li, W. andHou, B., Corrosion inhibition of mild steel in acidic solution by some oxo-triazole derivatives, Corros. Sci., 51, 2588 (2009).

16. Ferreira, E.S., Giacomelli, C., Giacomelli, F.C. andSpinelli, A., Evaluation of the inhibitor effect of 1 ascorbic acid on the corrosion of mild steel, Mater. Chem.Phys., 83, 129 (2004).

17. Paskossy, T., Impedance of rough capacitive electrodes, J. Electroanal. Chem, 364, 111 (1994).

18. Growcock, F.B. andJasinski, J.H., Time-resolved impedance spectroscopy of mild steel in concentrated hydrochloric acid = Spectroscopied'impédance de l'acierdouxdansl'acidechlorhydriqueconcentré, $J$. Electrochem. Soc., 136, 2310 (2010).

19. Abd El-Rehim, S.S., Khaled, K.F. andAbd El-Shafi, N.S., Electrochemical frequency modulation as a new technique for monitoring corrosion inhibition of iron in acid media by new thiourea derivative, Electrochim. Acta, 51, 3269 (2006).

20. Lebrini, M., Lagrenee, M., Vezin, H., Gengembre L. andBentiss, F., Electrochemical and quantum chemical studies of new thiadiazole derivatives adsorption on mild steel in normal hydrochloric acid medium, Corros. Sci., 47, 485 (2005).

21. Bessone, J., Mayer, C., Tuttner, K. and Lorenz, W., AC-impedance measurements on aluminium barrier type oxide films, J. Electrochim. Acta, 28,171 (1983).

Egypt.J.Chem. 60 , No. 4 (2017) 
22. Kus, E. and Mansfeld, F., An evaluation of the electrochemical frequency modulation (EFM) technique, Corros. Sci., 48, 965 (2006).

23. Abdel-Rehim, S.S., Khaled, K.F. and Abd-Elshafi, N.S., Electrochemical frequency modulation as a new technique for monitoring corrosion inhibition of iron in acid media by new thiourea derivative, Electrochim. Acta, 51, 3269 (2006).

24. Bockris, JO.andSwinkels, DAJ.,Adsorption of decylamine on Solid Metal Electrodes, $J$. Electrochem. Soc., 111, 736 (1964).

25. Lee,HP. andNobe, K.,Kinetics and Mechanisms of $\mathrm{Cu}$ Electrodissolution in Chloride Media, $J$. Electrochem. Soc., 133, 2035 (1986).

26. Ashassi-Sorkhabi, H., Shabani, B., Aligholipour, B. andSeifzadeh, D., The effect of some Schiff base on the corrosion of $\mathrm{Al}$ in $\mathrm{HCl}$ solution, Appl.Surf. Sci., 252, 4039 (2006).

27. Li, Y., Zhao, P., Liang, Q. and Hou, B., Berberine as a natural source inhibitor for mild steel in $1 \mathrm{M}$ H2SO4, Appl. Surf. Sci., 252, 1245 (2005).

28. Saleh, MM andAtia, AA, Effects of structure of the ionic head of cationic surfactant on its inhibition of acid corrosion of mild steel, J. Appl. Electrochem. 36, 899 (2006).

29. Li,XH., Deng, SD. and Fu, H., Synergism between red tetrazolium and uracil on the corrosion of cold rolled steel in H2SO4 solution, Corros. Sci., 51, 1344 (2009).

30. Shettya, S.Divakara andPrakashS., Inhibition of mild steel corrosion in acid media by N-benzyl$\mathrm{N}^{\prime}$-phenyl thiourea, Metallic Corrosion Inhibitors, Oxford: Pergamon Press, 27, 216 (2008).

31.Frumkin,AN.,Zeitschriftfur PhysikalischeChemie,1925, 116, 466. [publishing corporation, New York, 1963].

32. Bhajiwala, HM.and Vashi, RT.,Ethanolamine, diethanolamine and triethanolamine as corrosion inhibitors for zinc in binary acid mixture $\left(\mathrm{HNO}_{3}+\right.$ $\left.\mathrm{H}_{3} \mathrm{PO}_{4}\right)$, Bull. Electrochem., 17, 441 (2001).

33. Umoren,SA., Inhibition of aluminum and mild steel corrosion in acidic medium using Gum Arabic, Cellulose, 15, 751 (2008).

34. Oguzie, EE., Li, y. and Wang, FH., Corrosion effect of allylthioureaon bulk nanocystalline Ingot iron in diluted acidic sulphates solutions, ElectrochimActa, 52, 3950 (2007).
35. Mehaute, AH. and Grepy, G., Introduction to transfer and motion in fractal media: The geometry of kinetics, Solid State Ionics, 9-10, 17 (1989).

36. Khaled,KF., Molecular simulation, quantum chemical calculations and electrochemical studies for inhibition of mild steel by triazoles, Electrochim. Acta, 53, 3484 (2008).

37. Desai, MN., Corrosion inhibitors for aluminum alloys: A review, Werkst. Korros., 23, 475 (1972).

( Received: 27/2/ 2017; accepted : 2 /4 / 2017) 
تآكل الألومنيوم في محلول حمض الهيروكلوريك

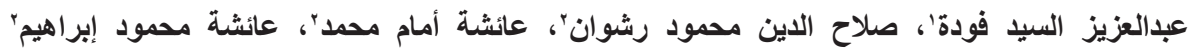

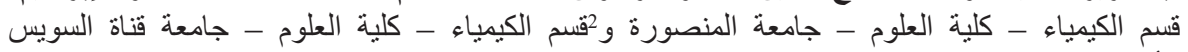

الأسماعيلية - مصر.

يعطينا هذا البحث نبذة عن أهمية الألو منيوم حيث أنه يدخل في العديد من التطبيقات الصناعية لأنه يمتلك كثافة

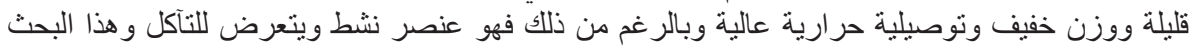
يدرس كيفية حماية الألو منيوم من التآكل.

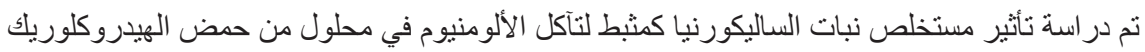

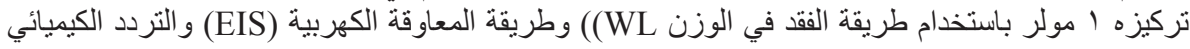

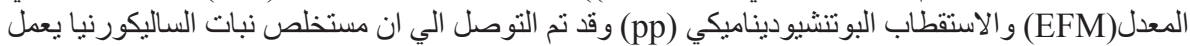
كمثبط طبيعي جيد لتآكل الألومنيوم في المحلول الحمئيوني.

ووجدنا أن كفاءة التثبيط ازدادت بزيادة نركيز المستخلص و أيضا بزيادة درجة الحرارة وهذا يوضح أن النيان

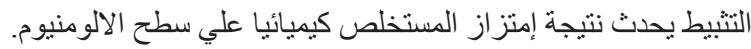

أثبتت دراسة طريقة الاستقطاب البوتنشيوديناميكي أن هذا المستخلص يعمل كمثبط مزدوج التأثير وقد

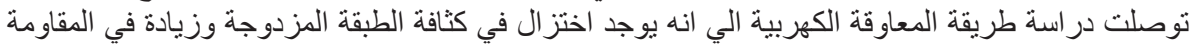

لانتقال الثحنات الكهربية.

ووجدنا أن امتصاص هذا المستخلص علي سطح الالومنيوم يتبع طريقة (Temkin) وقد وجد أن أن هذا

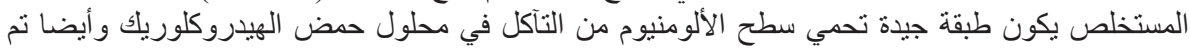

در اسة سطح الالومنيو باستخدام طُّريقة (SEM).

تم التوصل الي أن كل النتائج التي حصلنا عليها من كل الطرق المستخدمة السابقة متو افقة مع بعضها بدرجة 